\title{
Life as a knowledge broker in public health ${ }^{1}$
}

\author{
Paula Robeson, Maureen Dobbins, and Kara DeCorby
}

\begin{abstract}
Program objective - Knowledge brokers (KBs), like clinical librarians (CLs), are information professionals involved in the promotion of evidence-informed decision-making (EIDM). As with CLs, the impact of literatureevaluating KBs on the health sector is sparse, and there is limited consensus on their role. To provide guidance to information professionals and organizations regarding the KB role, this paper describes a typical "day in the life" of a $\mathrm{KB}$ in delivering a program to promote EIDM among Canadian public health professionals. Setting - The KB program was implemented in a randomized controlled trial evaluating knowledge transfer and exchange strategies. Participants Public health managers at various levels within Canadian public health units or regional health authorities. Program The KB identified decision makers' (DMs) evidence needs; facilitated access to and use of high-quality evidence; assisted in decision making; and facilitated EIDM skill development. Results - The KB role, activities and related tasks, lessons learned, and challenges are described. Conclusion - Central themes included the importance of relationship development, ongoing support, customized approaches, and individual and organizational capacity development. The novelty of the $\mathrm{KB}$ role in public health provided a unique opportunity to assess the need for and reaction to the role and its associated activities.
\end{abstract}

\section{Introduction}

Knowledge brokers $(\mathrm{KBs})$ are information professionals involved in the promotion of evidence-informed decisionmaking (EIDM), about which little is written to guide those in this role. EIDM is the process through which the best available research evidence, along with evidence from multiple other sources, is systematically and critically considered for incorporation into policy and practice [1]. KBs are often metaphorically referred to as bridges [2-5] that link producers and users of evidence to facilitate two-way interaction and collaboration to identify issues, solve problems [6], and promote EIDM [7-11]. There is little consensus, however, on the KB role and the activities they provid [12]. KB activities target individuals $[7,13,14]$, groups and (or) organizations [15,16], and countries [17]. In each case, KBs are linked to a group of research users, skilled in research interpretation and application, able to communicate effectively with different users and assist in translating research into local contexts [8].

The evolving role of the clinical librarian (CL) is similar to that of the KB. Like KBs, CLs aim to support EIDM and education through the provision of timely, quality appraised, and targeted evidence at the point of need [18]. CL activities involve assisting clinicians with access to clinical practice guidelines and guideline development, intensive literature searching, and professional development related to EIDM
[19-21]. However, there is limited evidence of the effectiveness or cost-effectiveness of CLs [22,23].

This paper describes a typical "day in the life" of a KB involved in a randomized controlled trial (RCT) in which the $\mathrm{KB}$ was being evaluated in comparison with other, more passive knowledge transfer and exchange (KTE) strategies. The results of this RCT are being published elsewhere [24]. The $\mathrm{KB}$ aimed to identify the research evidence needs of decision makers (DMs); facilitate their access to and use of highquality research evidence; assist them in incorporating evidence into decision making; and facilitate capacity development in the EIDM process.

\section{Role description}

The $\mathrm{KB}$ role in this study included the following activities: (i) developing and maintaining relationships; (ii) facilitating capacity for EIDM; and (iii) assisting DMs in promoting organizational change to support EIDM. Additional tasks included conducting initial and ongoing assessments of DMs' skills and capacity for EIDM, staying current with emerging evidence, and information management.

\section{Developing and maintaining relationships}

One-to-one contact was essential in getting to know DMs and establishing credibility and trust. Tools including a laptop with e-mail, the Internet, Web conferencing ability, and a

P. Robeson, ${ }^{2}$ M. Dobbins, ${ }^{3}$ and K. DeCorby. McMaster University, 1685 Main Street West, Unit 302, 3rd Floor, Hamilton, ON L8S 1G5, Canada.

${ }^{1}$ The views expressed in this paper are those of the authors and do not necessarily reflect those of the Ministry of Health and Long-Term Care.

${ }^{2}$ Corresponding author (e-mail: probeson@ @ealth-evidence.ca).

${ }^{3}$ Maureen Dobbins is a career scientist with the Ontario Ministry of Health and Long-Term Care. 
personal digital assistant facilitated monthly communication with DMs as well as the ability to meet their needs in a timely and efficient manner. Additionally, face-to-face contact occurred during regional capacity development workshops and site visits. Another strategy used to develop and maintain relationships was the building of a network for the DMs. This has also been reported in the literature as a key $\mathrm{KB}$ activity [5,8,25-30]. A virtual networking forum was created through webinars.

\section{Facilitating knowledge and skill development}

Individual and organizational capacity development opportunities occurred during all virtual and face-to-face contacts. Topics covered included identification of the steps in the EIDM process, such as searching for, accessing, appraising, interpreting, and applying the available evidence to the local context. Additionally, capacity development activities involved role modelling, mentoring, promoting reflective practice, and providing guidance throughout the decisionmaking process.

The KB started with encouraging DMs to be critical consumers of information and moved on to facilitating capacity to critically appraise research evidence. In many cases, DMs brought forward their own information for advice and assistance in judging the quality of the evidence as well as identifying implications for local policies and practice. One participant brought forward an article from the provincial newspaper and asked, "Is this research valid?" The KB assisted the DM to appraise the methodological quality of the study, identify the key findings, and translate these findings into locally relevant action messages.

\section{Promoting organizational change}

Organizational factors such as culture, decision making, and capacity for EIDM are associated with research use [31]. Therefore, an important role component for KBs involves facilitating organizational change so as to promote a culture conducive to EIDM. Specific activities used included (i) promoting internal knowledge sharing (e.g., through team e-mail distribution, team meetings, management meetings); (ii) developing targeted resources (e.g., briefing notes to key stakeholders); (iii) encouraging DMs to act as role models (e.g., requiring evidence to support recommendations or ideas brought forward) and including components of EIDM in performance appraisals and staff professional development plans; (iv) encouraging collaboration with public health or academic libraries to assist in the development of efficient search strategies; and ( $v$ ) making links to key resources easily accessible.

\section{Initial and ongoing assessment}

A core $\mathrm{KB}$ activity involves the identification of strengths and needs [5] to tailor KTE strategies to DMs' needs and then assisting them in translating research evidence into local policy and practice [32-35]. During this study, DM assessments were conducted at the beginning of the study and every 3-4 months throughout the 1 year intervention. The information gathered during these assessments related to the individual, organization, broader context, and the evidence itself and was collected primarily through telephone contact, e-mail, and organizational documents. In some instances there was considerable variation between DMs' perceptions of their knowledge and skill in EIDM and those of the KB. For these cases the KB worked collaboratively and in a sensitive manner with DMs to assist them in recognizing their strengths and learning needs in this area.

\section{Scanning the horizon}

Electronic connectivity was important for staying current as new evidence and knowledge emerged. Therefore, a portion of time was spent "scanning the horizon" for new evidence and resources in the content areas as well as for KB- and KTE-related information. This activity involved maintaining subscriptions to related list serves, electronic distribution lists, and e-table of contents alerts from relevant journals, or Really Simple Syndication (RSS) applications on journals or Web sites that regularly check for new content.

\section{Information and knowledge management}

The volume of information received and shared between the $\mathrm{KB}$ and DMs was vast and in some instances overwhelming. Thus, knowledge management was essential for effective and efficient knowledge brokering. A good system for managing the volume of information ensured that the $\mathrm{KB}$ could respond quickly to requests from DMs. To facilitate knowledge management, software packages that facilitate management of DM information and references (e.g., RefMan or RefWorks) are most helpful.

\section{Additional outcomes}

The outcomes of the randomized controlled trail are being published elsewhere [24]. Regarding the role itself, the KB recognised that $(i)$ early face-to-face contact is essential for facilitating greater engagement between the KB and the DM; (ii) initial and ongoing needs assessments are helpful in tailoring the KB activities to the specific needs and issues faced by DMs in their local contexts; (iii) individual DMs and organizations should complete a self-assessment of their knowledge and skills related to EIDM at baseline; (iv) multiple DMs from each organization should be engaged in the knowledge brokering intervention as this would result in a critical mass of DMs working toward EIDM; and ( $v)$ senior administrators must be active participants in the KB intervention and in promoting organizational change conducive to EIDM. Additionally, specific knowledge and skills are required and challenges met in providing $\mathrm{KB}$ services to a widely dispersed, national group of public health organizations.

\section{Required knowledge and skills}

A KB should possess expertise in the EIDM process, literature searching, critical appraisal, and the ability to synthesize information and assist in translating evidence into different local contexts. A non-judgemental, respectful manner combined with excellent written and oral communication skills, and strong interpersonal skills are important for building rapport with target audiences and developing strong network ties. An understanding of the context, processes, and key influencers of both the research and target communities is essential to establishing credibility with DMs. As well, proven abilities in critical thinking, reflective practice, stra- 
tegic planning, and adult education were key factors in modelling EIDM behaviour to DMs. A commitment to lifelong learning combined with an inquisitive and flexible nature, are key KB attributes, along with a healthy sense of humour to lighten the learning process and cope with challenges as they arise.

These knowledge, skills, and personal attributes have been associated with the clinical librarian, and in some cases, personality traits were considered to be more important to effectiveness than knowledge and skills [19].

\section{Challenges}

The title of $\mathrm{KB}$ is not regulated, and there is no $\mathrm{KB}$ certificate or academic program to prepare $\mathrm{KBs}$ for the challenges they face. During this study there was little guidance, either in the literature or through networks, to assist in the development of the role or for evaluating progress. The lack of available resources to support the $\mathrm{KB}$ work was particularly challenging and highlighted the importance of regular interaction with the research team to avoid becoming very isolated. From an organizational perspective, the perceived (and real) lack of organizational support in local public health units posed barriers to EIDM. Frequent organizational and staffing changes impacted on relationship development and maintenance as well as knowledge management within the health units.

Providing $\mathrm{KB}$ services as part of a study posed specific challenges. The 1-year period was too short to accomplish the KB goals. Geographic regional workshops included participants with a range of skill levels. Upon reflection this diversity resulted in a less than optimal experience for some workshop attendees. Future workshops would likely be more effective if EIDM skill level determined which workshop participants attended rather than geographic location. Furthermore, because adaptation of evidence to local decision making was very challenging for most, the workshops should focus more on interactive strategies promoting dialogue and debate about research evidence and how to adapt the evidence for local implementation.

\section{Conclusion}

As the knowledge broker $(\mathrm{KB})$ role developed, the central themes that emerged included the importance of relationship development, ongoing support, customized approaches, and opportunities for individual and organizational capacity development. The novelty of the $\mathrm{KB}$ role in public health and the knowledge available regarding the similar clinical librarian $(\mathrm{CL})$ role provide a unique opportunity to assess the need for and reaction to the KB role and its associated activities. Overall, it was a very challenging but rewarding experience that provided many opportunities for the $\mathrm{KB}$ to reflect and further develop professionally.

\section{References}

1. Brownson RC, Gurney JG, Land GH. Evidence-based decision making in public health. J Public Health Manag Pract. 1999 Sep;5(5):86-97.

2. Lomas J. The in-between world of knowledge brokering. BMJ. 2007;334:129-32.
3. Verona G, Prandelli E, Sawhney M. Innovation and virtual environments: towards virtual knowledge brokers. Organization Studies. 2006;27(6):765-88.

4. Lavis JN. Research, public policymaking, and knowledgetranslation processes: Canadian efforts to build bridges. $J$ Contin Educ Health Prof. 2006;26(1):37-45.

5. Lyons R, Warner G, Langille L, Phillips SJ. Piloting knowledge brokers to promote integrated stroke vare in Atlantic Canada. In: Canadian Institutes of Health Research (CIHR) Institute for Population and Public Health, editor. Moving population and public health knowledge into action: A casebook of knowledge translation stories. Ottawa, Ont.: Canadian Institutes of Health Research (CIHR) Institute for Population and Public Health; 2006.

6. Kitson AL, Harvey G, McCormack B. Enabling the implementation of evidence based practice: a conceptual framework. Quality in Health Care. 1998;7:149-58.

7. Canadian Health Services Research Foundation. The theory and practice of knowledge brokering in Canada's health system. Ottawa, Ont.: Canadian Health Services Research Foundation; 2003.

8. Hartwich F, von Oppen M. Knowledge brokers in agricultural research and extension. In: Graef F, Lawrence P, von Oppen $\mathrm{M}$, editors. Adapted farming in West Africa: issues, potentials, and perspectives. Stuttgart, Germany: Verlag Ulrich E. Grauer; 2000. p. $445-53$.

9. van Kammen J, De SD, Sewankambo N. Using knowledge brokering to promote evidence-based policy-making: the need for support structures. Bull World Health Organ. 2006;84(8):608-12.

10. Jackson-Bowers E, Kalucy L, McIntyre E. Knowledge brokering. Focus on... 2006 Dec;(4). Available from: http://www.phcris.org.au/publications/focuson/.

11. Canadian Health Services Research Foundation. Knowledge brokering demonstration site competition. Ottawa: Canadian Health Services Research Foundation; 2004.

12. Canadian Health Services Research Foundation. National Forum on Knowledge Transfer and Exchange. 2006.

13. Canadian Health Services Research Foundation. Knowledge brokering in Canada's health system: what we're doing, what we're reading. Ottawa, Ont.: Canadian Health Services Research Foundation; 2003.

14. Lomas J. Improving research dissemination and uptake in the health sector: beyond the sound of one hand clapping. Hamilton, Ont.: McMaster University Centre for Health Economics and Policy Analysis; 1997. Report No. c97-1.

15. Lavis JN, Robertson D, Woodside J, McLeod C, Abelson J. How can research organizations more effectively transfer research knowledge to decision makers? Milbank $Q$. 2003;81(2):221-48.

16. Hargadon AB. Brokering knowledge: linking learning and innovation. Research in Organizational Behavior. 2002;24:4185 .

17. Oldham G, McLean R. Approaches to knowledge-brokering. 1997. Available from: http://www.iisd.org/pdf/2001/networks_ knowledge_brokering.pdf. 
18. Winning MA, Beverley CA. Clinical librarianship: a systematic review of the literature. Health Info Libr J. 2003 Jun 15;20(s1):10-21.

19. Harrison J, Sargeant SJE. Clinical librarianship in the UK: temporary trend or permanent profession? Part II: present challenges and future opportunities. Health Info Libr J. 2004 Dec 3;21(4):220-6.

20. Winning MA, Beverley CA. Clinical librarianship: a systematic review of the literature. Health Info Libr J. 2003 Jun 15;20(s1):10-21.

21. Wagner KC, Byrd GD. Evaluating the effectiveness of clinical medical librarian programs: a systematic review of the literature. J Med Libr Assoc. 2004;92(1):14-33.

22. Winning MA, Beverley CA. Clinical librarianship: a systematic review of the literature. Health Info Libr J. 2003 Jun $15 ; 20(\mathrm{~s} 1): 10-21$.

23. Weightman AL, Williamson J. The value and impact of information provided through library services for patient care: a systematic review. Health Info Libr J. 2005 Mar 6;22(1):4-25.

24. Dobbins M, DeCorby K, Robeson P, Ciliska D, Thomas H, Hanna S, et al. The power of tailored messaging: preliminary results from Canada's first trial of knowledge brokering. 2007 Dec 2.

25. Clark G, Kelly L. New Directions for Knowledge Transfer and Knowledge Brokerage in Scotland. Office of Chief Researcher Knowledge Transfer Team Briefing Paper. Scottish Executive Social Research; 2005 Sep 30. Available from: http://www. scotland.gov.uk/Publications/2005/09/2782919/29199.

26. Zook MA. The knowledge brokers: venture capitalists, tacit knowledge and regional development. Int J Urban Reg Res. 2004;28(3):621-41.
27. Loew R, Bleimann U, Walsh P. Knowledge broker network based on communication between humans. Campus-Wide Information Systems. 2004;21(5):185-90.

28. Wenger E, Snyder W. Communities of practice: the organizational frontier. Harv Bus Rev. 2000;78(1):139-45.

29. Wenger E. Communities of practice: learning, meaning, and identity. New York: Cambridge University Press; 1998.

30. Lee LL, Neff M. How information technologies can help build and sustain an organization's community of practice: spanning the socio-technical divide? In: Hildreth P, editor. Knowledge networks: innovation through communities of practice. Hershey Pa.: Idea Group Publishing; 2004. p. 165-83.

31. Dobbins M, Ciliska D, Cockerill R, Barnsley J, DiCenso A. A framework for the dissemination and utilization of research for health-care policy and practice. Online J Knowl Synth Nurs. 2002;9(1):149-160.

32. Dobbins M, DeCorby K, Twiddy T. A knowledge transfer strategy for public health decision makers. Worldviews EvidBased Nurs. 2004;1(2):120-8.

33. Lavis J, Davies H, Oxman A, Denis JL, Golden-Biddle K, Ferlie E. Towards systematic reviews that inform health care management and policy-making. J Health Serv Res Policy. 2005;10(3 Suppl 1):35-48.

34. Lavis JN, Ross SE, Hohenadel J, Hurley J, Stoddart GL, Woodward $\mathrm{C}$, et al. The role of health services research in $\mathrm{Ca}$ nadian provincial policy-making. 2000. Report No. 1997-021.

35. Lavis JN, Robertson D, Woodside J, McLeod C, Abelson J. How can research organizations more effectively transfer research knowledge to decision makers? Milbank $Q$. 2003;81(2):221-48. 